\title{
A Study in the Field of Welding of Different Materials
}

\author{
V. R. Mishra* and Ranjeet Kumar Singh \\ Department of Mechanical Engineering, GLBITM, Greater Noida - 201306, Uttar Pardesh, India; \\ hod.me@glbitm.org, ranjeet.singh@glbitm.org
}

\begin{abstract}
Objectives: The investigation was done with the aim of studying the influence of basicity index on mechanical properties of the structural steel. Methods/Statistical Analysis: In this experiment, influence of Basicity index on the welding characteristics was analyzed in the submerged arc welding by keeping all other variables like current, voltage and welding speed constant. The effects of wire/flux (Basicity index) on ultimate tensile strength, Microstructure and impact strength of the weld metal was investigated. Weld deposits on structural steel plates were made at different flux composition. In these experiment plates of dimension $14 \times 125 \times 250 \mathrm{~mm}$ was used for welding. The specimens were cut out from the welded plate to carry out various tests after performing the saw operation. Five different types of fluxes were used to weld the plates. Findings: The impact toughness values at room temperature increases with increase in basicity index of flux and highest micro hardness values are formed at the Heat Affected Zone (HAZ) regions for welded specimens.
\end{abstract}

Keywords: Dissimilar Metals, Steel, Welding

\section{Introduction}

Structural steel is the preferred materials for the structural engineering as well as manufacturing of pipeline tanks, railroad cars, and ship construction etc. The welding fluxes for these steels are commercially available but the flux compositions are patented and are not widely reported in literature. In the present work flux was developed with the help of the available literature for joining of structural steel. To take vantage of the developments in Structural steel metals, welding flux which reduces the effects of hydrogen induced cracking and develop rugged microstructures must be developed.

$\mathrm{In}^{1}$ worked with fluxes of the different bases found that the actual and ideal composition was not identical and also analysed a three flux system and found that weld metal carbon content and appeared to be not dependent of fluxes and analysed that variation in silicon content of the weld metal is determined by the value of basicity index and that degree of determination is greater and value of basicity index is less than two. $\operatorname{In}^{2}$ observed that many versions of Submerged arc welding SAW such as tandem arc, multiple wire, twin arc etc., are now available and widely used for certain applications. Also, it is possible to achieve deposition rates order of $50 \mathrm{~kg} / \mathrm{hr}$. Increase in deposition rates achieved by increasing the welding current which tends to make worse joint toughness. $\operatorname{In}^{-3}$ while discussing the influence of welding parameters on mechanical behaviour of ferrous metals, said that a number of determined parameters in SAW influence microstructure, bead geometry and weld chemistry. Some researchers realized that the mechanical properties of weld are influenced by the composition of the base metal and to a large extent by the weld bead geometry and shape relationship as well. Observed that choice of welding parameters has ample influence on the chemical composition of weld bead. Chromium, molybdenum and silicon elements displaying an increasing trend and manganese element displaying a decreasing trend with an increase in any parameter, viz voltage, current and speed ${ }^{4}$. An attempt was made to determine important welding parameters for composition of weld like $\mathrm{Cr}, \mathrm{Mn}$ and $\mathrm{Si}$ in the SAW process. Welding voltage is most for controlling the weld metal composition. In Taguchi method parameter design

${ }^{*}$ Author for correspondence 
can optimize the performance characteristics through the controlling of process parameter and can decrease the sensitivity of the system performance ${ }^{5}$. In SAW, process parameters interact in a complex manner that affects various characteristics of the weld bead ${ }^{6}$.

\section{Materials and Methods}

Welding parameter has a great influence over the properties of weld material. Welding parameters can change the mechanical properties and microstructures of weld materials. In this experiment by changing the flux (basicity index) and keeping all other parameter constant it is found out that results that effect basicity index on weld bead geometry micro hardness, toughness, microstructure, tensile strength, etc. The structural steel plates used as a work material of dimension $14 \times 125 \times 250 \mathrm{~mm}$. 10 plates of dimension $14 \times 125 \times 250 \mathrm{~mm}$ were used for welding. These plates chamfered on $250 \mathrm{~mm}$ side and $\mathrm{V}$ grooves was made at 60 degrees of joining the plates and tacking on back side of plates using manual arc welding so that, keeping these plate on leveling mistake. After performing SAW operation, the specimens were cut from the welded plate to carry out various tests. After tacking, put specimen on base plate of SAW machine, clamped the specimen with base plate using clampers then by putting 5 different kinds of flux one by one in hopper, welding was done in $\mathrm{V}$ grooves of 5 plates. The experiments have been conduct on Submerged Arc Welding Machine (Tornado Saw M-800 transformer and FD 10-200T welding tractor available at P.E.C. Chandigarh. Figure 1 shows the submerged arc welding equipment.

Based on the value of basicity index, the flux is coined as acidic or basic. One of the main differences between basic and acidic fluxes is their ability to relieve the molten

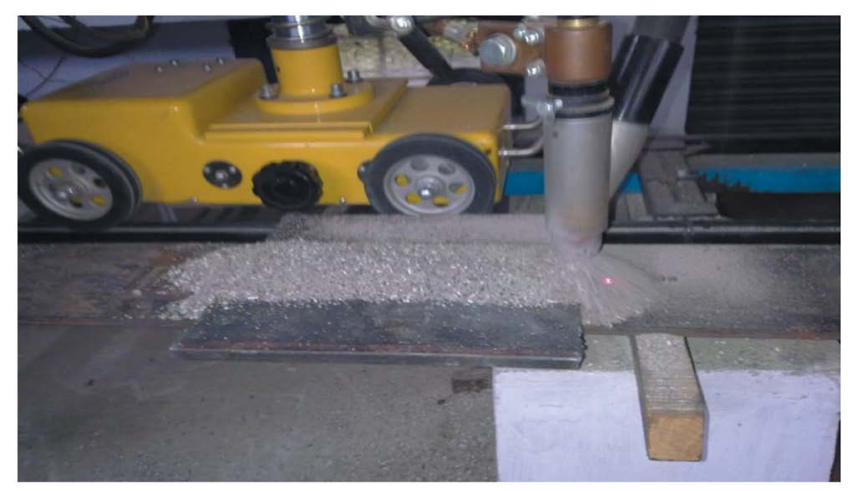

Figure 1. Submerged Arc welding of plates. metal of residual sulphur and phosphorus. For the preparation of flux, different compounds viz., $\mathrm{CaF}_{2}, \mathrm{CaO}$, $\mathrm{Na}_{2} \mathrm{O}, \mathrm{MnO}, \mathrm{SiO}_{2}, \mathrm{Al}_{2} \mathrm{O}_{3}, \mathrm{MgO}, \mathrm{TiO}_{2}, \mathrm{FeO}$ were used. The major compounds of coating are shown in Figure 2. The solution of sodium silicate ( $20 \%$ weight of flux) binder was mixed with dry powder and it was mixed for $10 \mathrm{~min}$. For better arc stability Sodium silicate was also added. The mixture flux was dried in air for $24 \mathrm{~h}$ and then baked in the pit furnace at $650^{\circ} \mathrm{C}$ for nearly $4 \mathrm{~h}$. The flux was crushed and sieved after cooling. Fluxes were kept in air-tight bags after done sieving. By using this method, we make 5 different kinds of flux. Chemical composition of Base metal and that of electrode is shown in Tables 1 and 2.

\section{Results and Discussions}

Table 3 shows results for the weld bead reinforcement and penetration. It can be analysed that increasing flux basicity showed a reduction in both bead width and

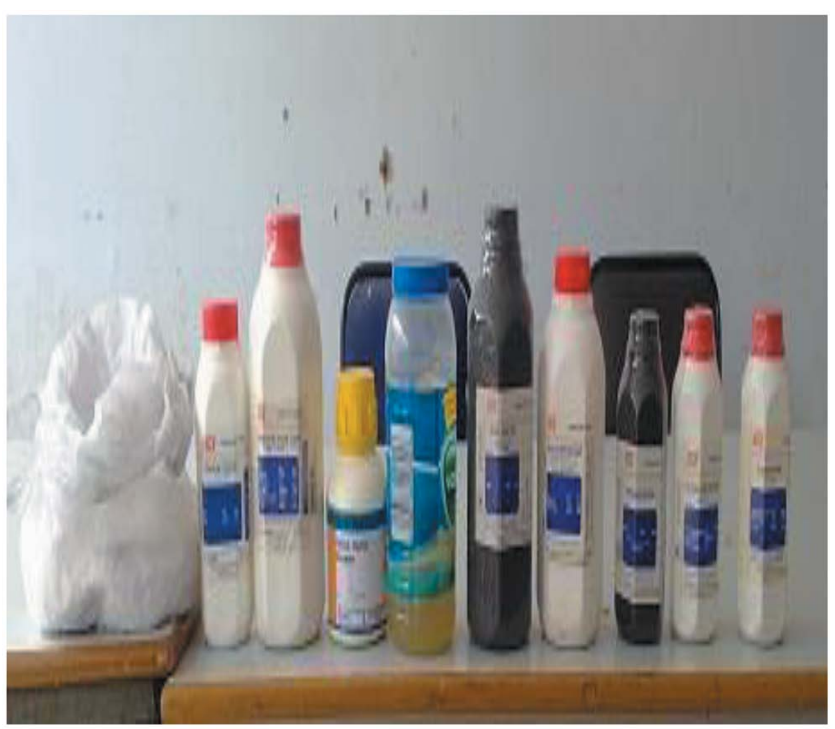

Figure 2. Major compounds of coating.

Table 1. Chemical composition of base metal

\begin{tabular}{llllllll}
\hline $\mathrm{C}$ & $\mathrm{Si}$ & $\mathrm{Mn}$ & $\mathrm{P}$ & $\mathrm{S}$ & $\mathrm{Cu}$ & $\mathrm{Nb}$ & $\mathrm{Ti}$ \\
\hline 0.25 & 0.24 & 0.47 & 0.03 & 0.02 & 0.09 & 0.07 & 0.009 \\
\hline
\end{tabular}

Table 2. Chemical composition of electrode

\begin{tabular}{lllllll}
\hline C & Mn & P & S & Cu & Nb & B \\
\hline 0.05 & 0.1 & 0.01 & 0.02 & 0.09 & 0.004 & 0.07 \\
\hline
\end{tabular}


penetration. All beads deposited for all types of flux were well shaped with fine ripples. The best bead was F2 in F position. Eighteen specimens of dimension $10 \times$ $10 \times 55 \mathrm{~mm}$ were prepared on milling machine, 3 from each plate. After that the specimens tested on Charpy toughness test machine.

The average value of impact toughness can be taken as the average of each specimen of base material in Figure 3 and weld metals at room temperature are shown in Table 4. From the Table 5 can be concluded that impact toughness decreases with the increase in basicity index. In all the specimens average value of impact toughness is lower than that of base metal impact toughness value except F1 value. In the present work micro hardness measurements were covered out in all weld regions of the test specimens of size $10 \mathrm{~mm} \times 10 \mathrm{~mm} \times 55 \mathrm{~mm}$, cut from the weld coupon as shown in Figure 4.

These specimens were polished and mounted on micro hardness tester, $250 \mathrm{gm}$ load was applied and reading was taken shown in Figure 5. Micro hardness measurement was taken at the base metal and weld pool interface shown in Figure 6. It was reported that with the increase of flux basicity, the micro hardness values decreased in weld and heat affected zone, very likely due to the decrease of $\mathrm{C}$

Table 3. Result for weld bead geometry

\begin{tabular}{llll}
\hline Sr. No. & $\begin{array}{l}\text { Bead Width } \\
(\mathrm{mm})\end{array}$ & $\begin{array}{l}\text { Bead } \\
\text { Reinforcement } \\
(\mathrm{mm})\end{array}$ & $\begin{array}{l}\text { Penetration } \\
(\mathrm{mm})\end{array}$ \\
\hline F 1 & 17.23 & 1.76 & 5.1 \\
F 2 & 17.10 & 1.68 & 4.96 \\
F 3 & 16.70 & 1.62 & 4.92 \\
F 4 & 16.10 & 1.35 & 4.62 \\
F 5 & 16.29 & 1.28 & 4.47 \\
\hline
\end{tabular}

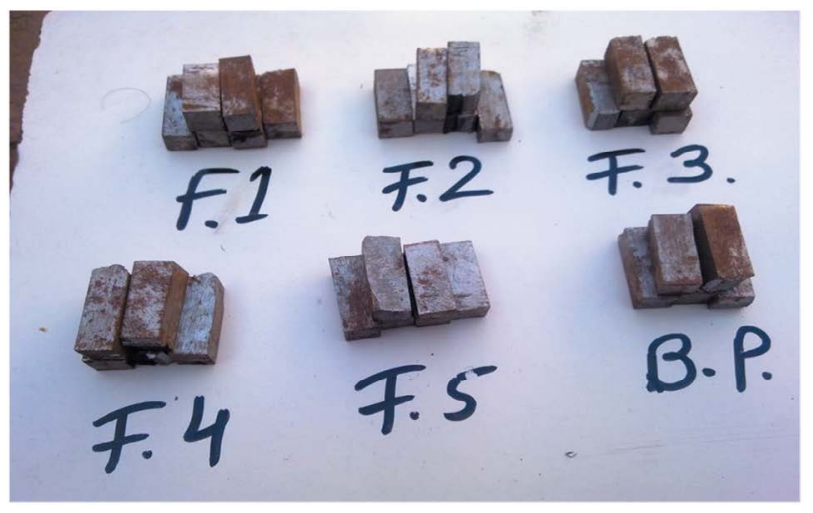

Figure 3. Specimens after impact testing.

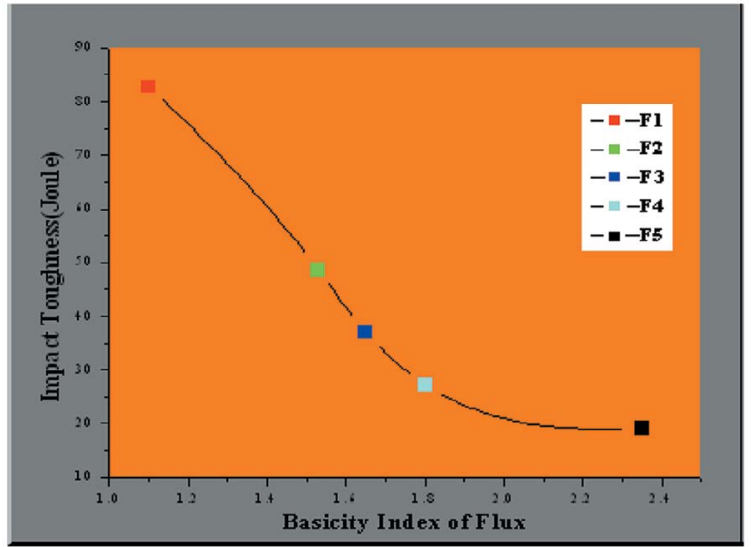

Figure 4. Average impact test results for different 5 flux.

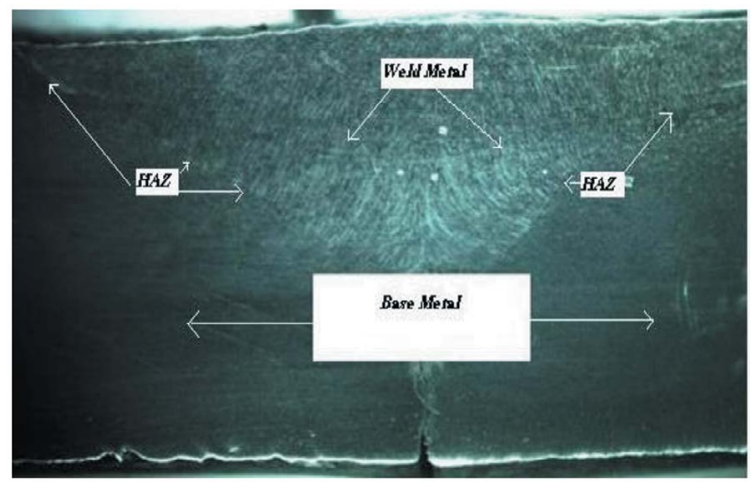

Figure 5. Different phases of weld specimen.

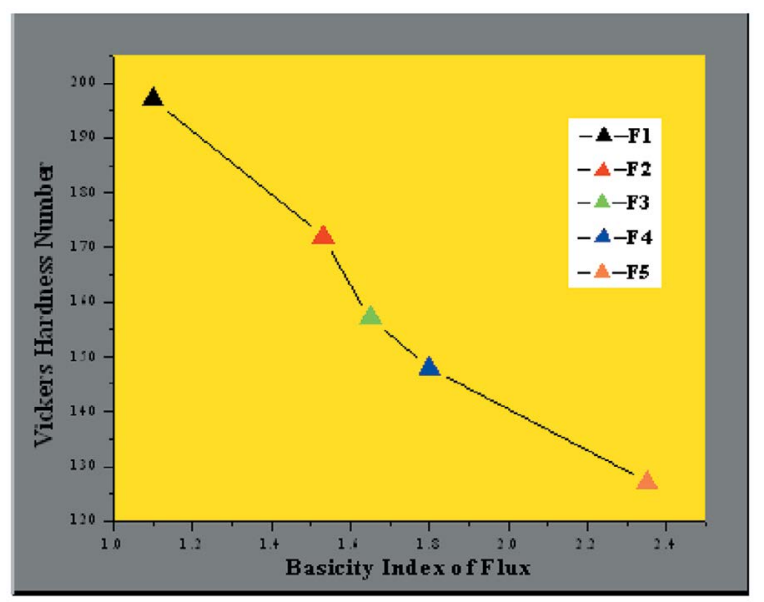

Figure 6. Micro hardness of welding specimen at centre of weld of different 5 fluxes.

and Si. From all the test specimens, the highest value of hardness was reported in the Heat affected region. The hardness value of the Heat Affected Zone (HAZ) and weld regions was different for all the test specimens. It is clear 
Table 4. Charpy V- Notch Impact Test Results of all welds (Joule)

\begin{tabular}{llll}
\hline Sr.No. & $\begin{array}{l}\text { Basicity } \\
\text { Index }\end{array}$ & Charpy Test (joule) & $\begin{array}{l}\text { Average of } \\
\text { toughness } \\
\text { value (joule) }\end{array}$ \\
\hline Flux & $\begin{array}{l}\text { Base } \\
\text { metal }\end{array}$ & $75-64-80$ & 73 \\
F 1 & 1.10 & $72.56-92.79-82.87$ & 82.74 \\
F 2 & 1.53 & $53.42-43.78-48.56$ & 48.58 \\
F 3 & 1.65 & $35.52-42.85-32.46$ & 36.94 \\
F 4 & 1.80 & $22.45-32.52-26.78$ & 27.25 \\
F 5 & 2.35 & $19.63-15.75-21.75$ & 19.04 \\
\hline
\end{tabular}

Table 5. Micro hardness values at base metal and welded region

\begin{tabular}{lrrrrrrrrrr}
\hline \multicolumn{1}{c}{ Distance In mm From Centre of Weld Metal } \\
\hline Sr.No. & $-16-12-8-4 ~ 04812$ & 16 \\
\hline F 1 & 110 & 238 & 217 & 195 & 200 & 197 & 205 & 224 & 104 \\
F 2 & 104 & 199 & 187 & 175 & 179 & 172 & 185 & 201 & 105 \\
F 3 & 105 & 178 & 165 & 164 & 164 & 157 & 166 & 188 & 108 \\
F 4 & 104 & 169 & 156 & 154 & 150 & 148 & 154 & 167 & 104 \\
F 5 & 106 & 143 & 134 & 127 & 128 & 127 & 132 & 141 & 110 \\
\hline
\end{tabular}

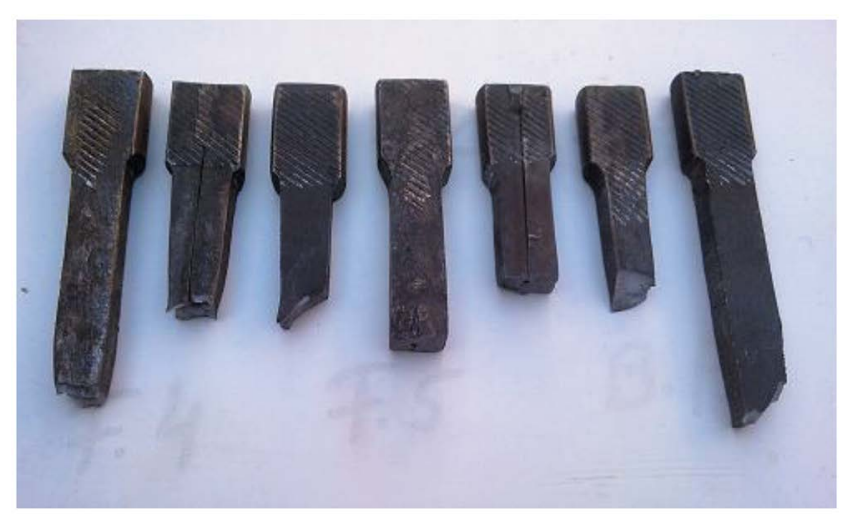

Figure 7. Specimens after tensile test.

from the graph that the max. Average micro hardness was observed at $\mathrm{HAZ}$ region of F1.

Computerized Universal tensile testing machine was used to carry out tensile tests. Figure 7 shows the specimens after tensile test. Firstly, the ends of the specimen were gripped in a tensile testing machine and load was applied on the machine. After that load was increased on both end till the specimen fractured. This was the method of testing the samples on ultimate tensile machine. The load dial of the machine and extensometer were used for measuring the tensile strength and elongation for noting the previously marked gauge length. The reported readings were used to plot the graph between stress and star in. The two broken pieces of tensile specimen were placed as if fixed together and the two gauge marks were noted for measuring the distance. Also, the area of the fracture was noted.

The effect of various fluxes on Ultimate Tensile Strength and from Table 6, it appears that maximum ultimate tensile strength was observed for F1 i.e. $112.260 \mathrm{KN}$ and the lowest ultimate tensile strength obtained from F5 i.e. $85.840 \mathrm{KN}$. It is clear from the graph that with the increase in basicity index tensile strength observed was decreases. It was concluded that an increase in $\mathrm{Mn}$, and $\mathrm{C}$ individually produced in increase of tensile strength as visible in Figure 8. The cross section of the weld samples was examined under the optical microscope to determine the structure. Microscopic means invisible to the eye unless aided by a microscope. In this test the specimen after cutting rubbed with emery papers of size no. $100,220,400,600,800,1000,1500,2000$. The pieces were polished and etched with nital etchant. Figure 9 are optical micrograph showing the microstructures of structural steel at magnifications of x100 of base metal, HAZ and weld metal respectively. The micro- graph of the figures reveals the presence of typical ferrite (bright)-pearlite

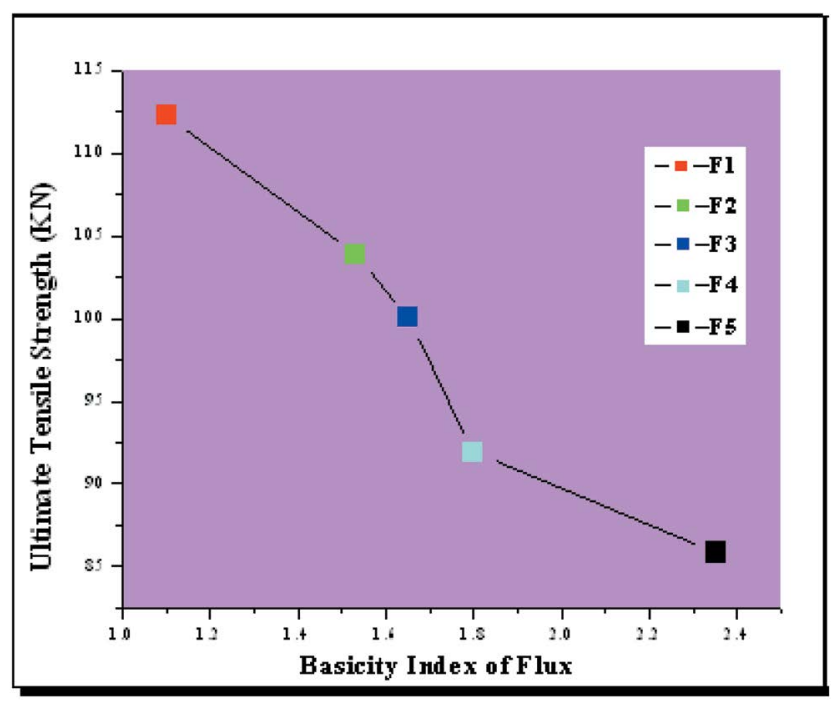

Figure 8. Ultimate tensile load vs. different 5 types of flux. 
Table 6. Ultimate tensile strength value at welded region

\begin{tabular}{llll}
\hline Sr. No. & Flux & Basicity Index & $\begin{array}{l}\text { Ultimate Tensile Load } \\
(\mathrm{KN})\end{array}$ \\
\hline 1 & F1 & 1.10 & 112.260 \\
2 & F2 & 1.53 & 103.900 \\
3 & F3 & 1.65 & 100.060 \\
4 & F4 & 1.80 & 91.900 \\
5 & F5 & 2.35 & 85.840 \\
\hline
\end{tabular}

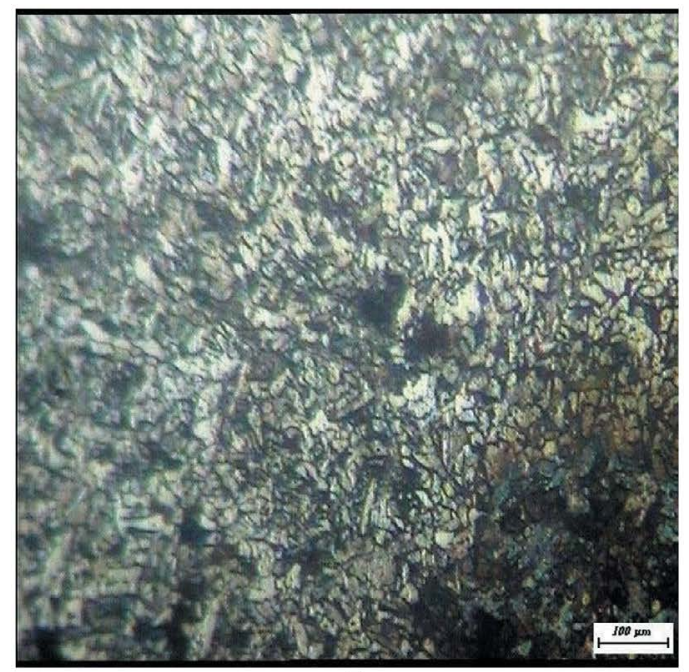

(a)

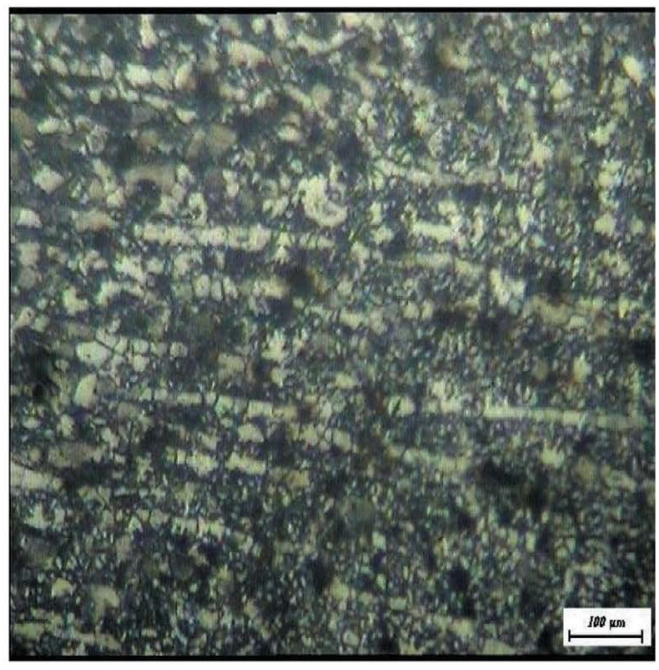

(b) Heat Affected Zone

Figure 9. Microstructure of flux 4 x100 magnification. (a) Weld zone. (b) Heat affected zone.

(dark) microstructure. It can be said that the distribution of the microstructure in the weld consists of three distinctly different microstructural regions, such as the dendritic region at interface, reheat refined coarse grain region and reheat refined fine grain region.

\section{Conclusions}

The present study was done to analyses the influence of flux on the welding characteristics in the submerged arc welding by keeping all other variable keeping constant like welding speed, current and voltage. Development of fluxes for submerged arc welding of structural steel achieved successively. Increasing flux basicity produced a reduction in both bead width and penetration. The impact toughness values at room temperature increases with increase in basicity index of flux. Highest micro hardness values are formed at the HAZ regions for welded specimens. A slight decrease in micro hardness values with increase in basicity index is observed. The micro hardness values decreased in each zone likely due to the decrease of $\mathrm{C}$ and $\mathrm{Si}$. The micro hardness value was increased in fine grain structure is observed. Ultimate tensile strength values are dependent on the basicity index. It can be concluded that more is the basicity index lesser will be the ultimate tensile strength. It was concluded that an increase in $\mathrm{Mn}$, and $\mathrm{C}$ individually produced in increase of tensile strength. Ultimate tensile strength values were also satisfactory for all weld joints.

\section{References}

1. Devis MLE. How submerged arc flux composition influence element transfer. Weld Pool Chemical and Metal. 1980; 8:289-310.

2. Chandel RS, Seon HP, Cheong FL. Effect of metal powder addition on Mechanical properties of submerged arc welds. Journal of Materials Science. 1998:1785-6.

3. Srivastava BK, Tewari SP, Jyoti P. A review on effect of arc welding parameter on mechanical behaviour of ferrous metals. International Journal of Engineering Science and Technology. 2010; 2(5):1425-32.

4. Karun, Jindal S, Gupta RD. Effect of saw parameters on weld element transfer in SS316. International Journal of Current Engineering and Technology. 2011; 1(1):110-14.

5. Elsayed EA, Chen A. Optimal levels of process parameters for products with multiple Characteristics. International Journal Production Research. 1993; 31:1117-32. https://doi.org/10.1080/00207549308956778

6. Myers R, Montgomery D. Response surface methodology. Technometrics. 1989; 31(2):137-57. https://doi. org/10.2307/1268813 